\title{
Does the bank risk concentration freeze the interbank system?
}

\author{
Marcella Lucchetta* \\ Universita' Ca' Foscari di Venezia, Dipartimento di Economia, Italy
}

\section{A R T I C L E I N F O}

\section{Article history:}

Received 19 May 2014

Received in revised form 2 April 2015

Accepted 2 April 2015

Available online 17 April 2015

\section{Keywords:}

Interbank system

Risks concentration

\begin{abstract}
A B S T R A C T
Probably, one test of the stability of the banking system is to evaluate how risky assets are distributed across banks' portfolios and the implications for the contagion via interbank relations. This paper explores theoretically a bank sector with risks concentration and the functioning of interbank markets. It employs a simple model where banks are exposed to both credit and liquidity risk that suddenly correlate over the business cycle. We show that risk concentration makes interbank market breakdowns more likely and welfare monotonically decreases in risk concentration.
\end{abstract}

(c) 2015 Elsevier Inc. All rights reserved.

\section{Introduction}

A key feature of the 2007-2008 financial crisis has been the disruption and prolonged malfunctioning of interbank markets (see, e.g. Acharya \& Merrouche, 2013; Afonso, Kovner, \& Schoar, 2011; Ciccarelli, Maddaloni, \& Peydró, 2013; Heider, Hoerova, \& Holthausen, $2010^{1}$ ) sometimes related to the interbank network structure (Georg, $2013^{2}$ ). This has come as a surprise to most observers, since interbank markets have been functioning smoothly historically, even in the face of severe stress episodes

\footnotetext{
* Tel.: +39 3356955599 .

E-mail address: lucchett@unive.it

${ }^{1}$ Ciccarelli et al. (2013) find that financial intermediaries are extremely fragile in the EU. The ECB effectively partly substituted the interbank market and, in turn, induced a subsequent softening of lending conditions.

2 Georg (2013) shows that networks with the central bank that intervene, solving market incompleteness, are more stable than random networks.
} 
such as the LTCM failure (Furfine, 2000) and it attaches importance to policy interest rate for loan portfolio risk and bank liquidity as recent found in Giulioni (2015).

Theoretical research addressing why interbank markets may not function properly has provided explanations based on informational and market frictions such as: asymmetric information or market incompleteness (e.g. Acharya \& Skeie, 2011; Flannery, 1996; Freixas \& Jorge, 2008; Georg, 2013; Gale \& Yorulmazer, 2012; Heider et al., 2010); information contagion where the poor performance of each bank conveys potential bad news about the common factor affecting loan returns (Acharya \& Yorulmazer, 2008); market power (e.g. Acharya, Gromb, \& Yorulmazer, 2012; Cai \& Thakor, 2008); and malfunctioning secondary asset markets (e.g. Diamond \& Rajan, 2005, 2008; Gorton \& Huang, 2004, 2006).

Since the early 2000s, however, there has been increasing evidence of a positive relationship between measures of systemic risk in major banking systems and bank concentration. ${ }^{3}$ This evidence raises the question of whether the correlation of risks possibly induced by higher bank risk concentration could have a significant impact on the functioning of interbank markets and welfare, and if so, why. To our knowledge, this question has not been addressed in the literature. A recent study discuss the international portfolio diversification of Miralles-Marcelo, del Mar Miralles-Quirós, and MirallesQuirós (2015), but aside from the interbank market and the correlation between liquidity risk and credit risk.

Specifically, in this paper we explore the implications of banking system risk concentration for the functioning of interbank markets in a model where banks are exposed to both credit and liquidity risk. Indeed, as show in Cornett, McNutt, Strahan, and Tehranian (2011), Brunnermeier (2009), Covitz and Downing (2007) and Ericsson and Renault (2006) credit and liquidity risk may dramatically correlate over the business cycle especially during financial crisis. Moreover, Da Silva and Divino (2013) show that credit risk is pro-cyclical and default risk depends on structural features, underlining the banking regulation role in presence of credit and liquidity shocks.

The line of inquiry of this paper is related to, and builds on, the contributions by Ibragimov, Jaffee, and Walden (2011) and Wagner (2010, 2011), who show that inefficiencies may arise from individual bank diversification, which does not necessarily result in a more resilient banking system. However, these papers do not consider interbank markets and multiple sources of risks, such as credit and liquidity risk, as we do. ${ }^{4}$

We build a simple model along the lines of Diamond and Dybvig (1983) and Bhattacharya and Gale (1987) models, where banks are exposed to both credit and liquidity risk, and there are no informational or market frictions. The market failure in our economy is that contracts are incomplete and therefore, not all risks can be insured. Interbank market breakdowns are defined as parameter configurations under which there is no interbank market equilibrium, and banks implement autarkic allocations.

We show that an increase in the concentration of risks, possibly arising from concentrated market structures, makes interbank markets breakdowns more likely. Differing from the previous literature, our results are not driven by asymmetric information, market power or dysfunctional secondary markets. Rather, they are explained by credit and liquidity risks correlation as suddenly happens over the business cycle. As an example, the ability to diversify these risks may be prevented by risk management diseconomies associated with large sizes of financial institutions and the wide scope and complexity of their activities. Indeed, systemically important financial institutions (SIFIs) are seen as institutions

\footnotetext{
3 Group of Ten (2001) concluded that "Evidence suggests that [risk] interdependencies between large and complex banking organizations have increased over the last decade in the United States and Japan, and are beginning to do so in Europe. Although a causal link has not been established, these increases are positively correlated with measures of consolidation." A positive relationship between bank concentration and measures of bank systemic risk is found in Boyd, De Nicolò, and Loukoianova (2009a) and Boyd, De Nicolò, and Jalal (2009b). During the periods of intense consolidation of the last decade, De Nicolò and Kwast (2002) found increased risk interdependencies among U.S. large and complex banking organizations. Risk profiles of large and complex U.S. and European banks were also found to have increased in the U.S. in Europe, and globally in De Nicolò, Hayward, and Bhatia (2004a), De Nicolò, Bartholomew, Zaman, and Zephirin (2004b), Stiroh (2004), Hartmann, Straetsman, and de Vries (2005), Stiroh and Rumble (2006), and Houston and Stiroh (2006).

4 This paper can be viewed as also indirectly related to the papers by Gai et al. (2011) and Anand et al. (2012), as they analyze numerically how network connections and different exogenous interbank structures affect banks' short term funding but do not consider banks' choice of risk concentration and welfare implications, as we do (see Section 6).
} 
to be carefully monitored by regulator as a potential source of systemic risk (see e.g. ECB Financial Stability Review, December 2009).

In Section 2 we describe the model. The model set-up captures in stylized form the important distinction between diversification of a banking firm and diversification of the financial system emphasized and documented empirically by De Nicolò and Kwast (2002). Banks can be perfectly diversified individually, but aggregate risk in the banking system can be either perfectly diversified or concentrated across banks. As the system becomes composed of fewer and larger banks, each bank will be more diversified individually, but the banking system will be less diversified, since a larger fraction of banks is exposed to the same aggregate shocks. In the model, the degree of banking system diversification is parameterized between the two extremes of perfect diversification and maximal concentration.

Section 3 defines the interbank equilibrium. Interbank market breakdowns are simply defined as situations in which the interbank equilibrium does not exist and is replaced by the autarkic equilibrium, where each bank is disconnected from each other.

In Section 4, the existence of interbank equilibria is established for the two extreme cases of a perfectly diversified and a maximally concentrated banking system. Then, it is shown that for a large set of economies, the size of the set of interbank equilibria under a diversified banking system is always strictly larger than that of a concentrated banking system for any level of credit and liquidity risk. This result indicates that in the presence of aggregate risk, a diversified banking system is likely to be less prone to interbank market breakdowns.

Section 5 defines the welfare properties of interbank and autarkic allocations. When an interbank equilibrium exists, it gives a higher expected utility to depositors than the autarkic equilibrium, but importantly, depositors' welfare is monotonically decreasing in the degree of risk concentration.

Section 6 provides an example extending the model to capture the Shehzad and De Haan (2013) findings. Their results suggest that stock prices of large banks were affected more during the crisis than those of small banks. They also find that managerial efficiency, loan quality, leverage, and the volume of outstanding loans affect bank stock prices. Thus, in our extension, risk concentration and a high probability of interbank market breakdowns is due to risk management diseconomies of scale and scope affecting large and complex financial firms. Specifically, when our model is modified by introducing a risk control technology with decreasing returns over a certain investment threshold, banks will choose a level of risk concentration that increases in size. Such level is higher the larger is the cost of risk control arising from the internal organization of large and complex firms. This result suggests improvement of risk control technologies in large and complex financial institutions and in regulatory bodies may be policy concerns as important as other polices considered in the literature to minimize the probability of interbank market breakdowns.

Section 7 concludes. Proofs of all propositions are in the Appendix.

\section{The model}

There are three periods, $t=0,1,2$, and one risky asset that yields a random return at date 2 per unit invested at date 0 . It can assume two values, $R=R^{h}$, and $R=R^{l}$, with the probabilities specified below. If a portion of the investment in this asset is liquidated at $t=1$, it yields a certain return of $\lambda$ per unit invested. The fraction of the asset that is liquidated is denoted $\alpha$. It is assumed that $R^{h}>R>\lambda \geq 1^{l, 5}$, so that if storage is available, this technology will be dominated in rate of return in both dates and will be never used. This is not a strong assumption since in the special case $\lambda=1$, the long asset mimics the storage technology and can be liquidated to satisfy early consumers, as we define shortly, or to lend in the interbank market.

At date 0 consumers are endowed with one unit of the date 0 consumption good, which is assumed to be invested all in one bank. Consumers are uncertain about their time preferences: with probability $\mu$ they are early consumers, who want to consume at date 1 only, and with probability $1-\mu$ they

\footnotetext{
5 This implies that the expected value of the long asset is greater than one (the return of the storage technology). Furthermore, with the possibility to use interbank market, there is no need to hold costly liquidity.
} 
are late consumers, who want to consume at date 2 only. ${ }^{6}$ We assume that depositors have limited participation in the assets market thereby they need banking intermediation. ${ }^{7}$ Their preferences are represented by a utility function $U(c)$, twice continuously differentiable, increasing, and strictly concave. The fraction of early consumers is also random and can assume two values: $\mu=\mu^{h}$, and $\mu=\mu^{l}$, with $1>\mu^{h}>\mu^{l}>0$.

The banking sector is composed by $N$ ex-ante identical banks that invest consumer's endowments at date 0 . The banking sector is perfectly competitive, so that banks' objective is to maximize depositors' expected utility.

Each bank is exposed to liquidity and credit risk shocks. The realization of both shocks is observed by a bank at date 1 . We assume there is no aggregate uncertainty, so that the fraction of banks which is exposed to a given combination of credit and liquidity shocks is deterministic. However, the probabilities (and hence the distribution) of these banks at date 0 depends on an exogenous parameter $\sigma \in(0,1)$ that indexes the degree of concentration of liquidity and credit risk in the banking system.

Specifically, the fraction of banks that experience a given pair of realizations of credit and liquidity risk $(R, \mu)$ is given by the following table, with $p \in(0,1)$ and $q \in(0,1)$, where $p$ is the probability of a bank to have a high return and a low liquidity shock and $q$ is the probability of a bank to have a high return and a high liquidity shock. These probabilities, $p$ and $q$, are independent.

Returns $\backslash \mu$ Low High

\begin{tabular}{c|cc|} 
High & $\sigma p$ & $(1-\sigma) q$ \\
Low & $(1-\sigma)(1-q)$ & $\sigma(1-p)$ \\
\hline
\end{tabular}

Thus, as of date 1 , there are four types of banks:

$\begin{array}{ll}\text { type } 1 & \text { type } 2 \\ \text { type } 3 & \text { type } 4\end{array}$

Thereafter we refer to parameter $\sigma$ as an index of "risk concentration".

A fraction of banks $\sigma p$ (type 1) experiences a low liquidity shock and a high final date return on the asset; by contrast, a fraction of banks $\sigma(1-p)$ (type 4) experiences the reverse, that is, a high liquidity shock and a low final date return on the asset. Thus, credit risks and liquidity risks are perfectly positively correlated for type 1 and 4 banks.

Conversely, a fraction of banks $(1-\sigma) q$ (type 2 ) experiences a high liquidity shock but also a high final date return on the asset, whereas a fraction of banks $(1-\sigma)(1-q)$ (type 3$)$ a low liquidity shock but also a low final date return on the asset. Thus, credit risk and liquidity risks are perfectly negatively correlated for type 2 and 3 banks.

If $\sigma=0$, then the banking system is made of banks that diversify their credit and liquidity risks. By contrast, if $\sigma=1$, banks concentrate their credit and liquidity risks. As $\sigma$ increases, the banking system exhibits a higher concentration of risks for any given values of $(p, q)$.

\section{Interbank equilibrium}

Here we examine how well an interbank market works for any level of risk concentration (i.e. any $\sigma)$.

There is an interbank market where liquidity can be traded at the intermediate date. The amount of funds that each bank trade in the interbank market is denoted $b$ and the gross interbank rate is denoted by $r$.

\footnotetext{
${ }^{6}$ When $\lambda=1$, in this case early consumers receive 1 such that in expectation the incentive compatibility constraint is satisfied: i.e. late consumers receive $E[R]>1$.

7 This assumption is standard in the literature starting from the model of Diamond and Dybvig (1983).
} 
At date 0 , competitive banks maximize the expected utility of depositors. They choose the amount of borrowing $b$ (if positive, borrowing, if negative, lending) and the amount of asset to liquidate, $\alpha$, to solve:

$$
\underset{\alpha, b}{\operatorname{Max}} \Pi_{1}=\mu U\left(c_{1}\right)+(1-\mu) U\left(c_{2}\right)
$$

Subject to

$$
\begin{aligned}
& \mu c_{1}=\alpha \lambda+b \\
& (1-\mu) c_{2}=R(1-\alpha)-r b,
\end{aligned}
$$

where $r$ is the "interbank" rate, to be determined in the $t=1$ credit equilibrium.

Assume an interbank equilibrium exists. Substituting (3) in (2) through $b$,

$$
\mu c_{1}+(1-\mu) \frac{c_{2}}{r}=\alpha \lambda+\frac{R}{r}(1-\alpha) .
$$

The solution $\alpha^{*}$ will be the one that makes the bank's budget constraint the largest, i.e. that makes the right hand side of (4) the largest. Hence, the solution is given by:

$$
\alpha^{*}=0 \quad \text { if } \frac{R}{r}>\lambda \text { and } \alpha^{*}=1 \text { if } \frac{R}{r}<\lambda .
$$

Observe that the existence of a storage technology would not affect the conditions to liquidate the long asset. Indeed, as long as the long asset value at period 1 is lower that $\lambda$, it is always optimal to liquidate it.

A necessary condition for the existence of an interbank equilibrium is that

$$
r \in\left(\frac{R^{l}}{\lambda}, \frac{R^{h}}{\lambda}\right) .
$$

This is because if $r \leq \frac{R^{l}}{\lambda}$, by (4) all banks will not liquidate the investment in the risky technology, and by (2) they will wish to finance all date 1 consumption by borrowing. Thus, there would be no lenders, hence no interbank equilibrium. Likewise, if $r \geq \frac{R^{h}}{\lambda}$, by (5) all banks will liquidate the investment in the risky technology, and by (3) they will wish to finance all date 2 consumption by the repayments on lending at date 2 . But at date 1 there would be no borrowers, hence no interbank equilibrium.

Using (2), (3) and (5) in (1), bank $(R, \mu)$ solves:

$$
\underset{b}{\operatorname{Max}} \Pi_{1}=\mu U\left(\frac{\alpha^{*} \lambda+b}{\mu}\right)+(1-\mu) U\left(\frac{R\left(1-\alpha^{*}\right)-r b}{1-\mu}\right),
$$

the first order condition with respect to $b$ is

$$
U^{\prime}\left(\frac{\alpha^{*} \lambda+b}{\mu}\right)=r U^{\prime}\left(\frac{R\left(1-\alpha^{*}\right)-r b}{1-\mu}\right) .
$$

Thus, the solution of the bank problem is given by (5) and (7). Note that banks optimal choices are the liquidation decision $\alpha^{*}(R)$, which does not depend on $\mu$, and $b(R, \mu)$. The liquidation decision in response to the credit risk realization does not depend on the liquidity shock (in (5) nothing depends on $\mu$ ), but the borrowing decision depends on both shocks (by (7)).

We characterize equilibria for $\log$ utility preferences, i.e. $U(c)=\ln (c)$. The choice of this specification is motivated by simplicity and by the fact that for these preferences, date 1 spot market allocations and optimal banking allocations generally coincide in liquidity preference frameworks such as ours (see Allen \& Gale, 2007). Our results are robust to more general consumer utility specifications. It is easy to see in Eq. (7) that it is sufficient to adopt a consumer's utility function twice continuously differentiable, increasing, and strictly concave. Hence, these preferences can be viewed as a useful benchmark to judge differences in equilibriums and associated welfare properties in diversified and concentrated risk economies independently of efficiency wedges between market and banking allocations. 
Eq. (7) yields:

$$
\frac{\mu}{\alpha^{*} \lambda+b}=\frac{r(1-\mu)}{R\left(1-\alpha^{*}\right)-r b} .
$$

Solving (8), we have

$$
b(R, \mu)=\frac{1}{r}\left(\mu R\left(1-\alpha^{*}\right)-r(1-\mu) \alpha^{*} \lambda\right) .
$$

Since $r \in\left(\frac{R^{l}}{\lambda}, \frac{R^{h}}{\lambda}\right)$, by (5), optimal asset's liquidation is $\alpha^{*}\left(R^{l}\right)=1$ and $\alpha^{*}\left(R^{h}\right)=0$.

In sum, the four bank types have the following borrowing/lending positions

$$
\begin{aligned}
& b\left(R^{l}, \mu^{l}\right)=-\left(1-\mu^{l}\right) \lambda \\
& b\left(R^{l}, \mu^{h}\right)=-\left(1-\mu^{h}\right) \lambda \\
& b\left(R^{h}, \mu^{l}\right)=\frac{1}{r}\left(\mu^{l} R^{h}\right) \\
& b\left(R^{h}, \mu^{h}\right)=\frac{1}{r}\left(\mu^{h} R^{h}\right),
\end{aligned}
$$

and equilibrium in the interbank market requires

$$
\sigma p \frac{1}{r} \mu^{l} R^{h}+(1-\sigma) q \frac{1}{r} \mu^{h} R^{h}-(1-\sigma)(1-q)\left(1-\mu^{l}\right) \lambda-\sigma(1-p)\left(1-\mu^{h}\right) \lambda=0 .
$$

The above equation (10) is linear with respect to $r$ and has the unique solution:

$$
r^{*}=\frac{R^{h}\left(\sigma p \mu^{l}+(1-\sigma) q \mu^{h}\right)}{\left[(1-\sigma)(1-q)\left(1-\mu^{l}\right)+\sigma(1-p)\left(1-\mu^{h}\right)\right] \lambda} .
$$

Eq. (11) says that the interbank equilibrium rate raises as the liquidity needs and the opportunity cost of holding the asset, $R^{h}$, increase.

\section{Comparisons of equilibria}

In this section we identify conditions ensuring existence of equilibria for the extreme values of $\sigma$, and compare the set of parameters for which equilibria exists for such values.

Using (11) and $r^{*} \in\left(\frac{R^{l}}{\lambda}, \frac{R^{h}}{\lambda}\right)$, we obtain

$$
1 \geq \frac{\sigma p \mu^{l}+(1-\sigma) q \mu^{h}}{(1-\sigma)(1-q)\left(1-\mu^{l}\right)+\sigma(1-p)\left(1-\mu^{h}\right)} \geq \frac{R^{l}}{R^{h}} .
$$

We use (12) to assess the existence of interbank equilibria under two extreme cases, that of banking system's perfect diversification ( $\sigma=0)$, and that of maximal risk concentration in the banking system $(\sigma=1)$. The main result is summarized in the following proposition.

Proposition 1. For the perfect diversified economy $(\sigma=0)$ and for the perfect concentrated economy $(\sigma=1)$, the set of interbank equilibria is non-empty for any parameter configuration of credit and liquidity $\operatorname{risk}\left(\mu^{h}, \mu^{l}, R^{h}, R^{l}\right)$.

Now, we wish to compare the size of the set of economies, indexed by $p$ and $q$, for which equilibria exist for $\sigma=0$ and for $\sigma=1$.

We assess the equilibria domains defining two sets as below detailed. To this scope, we measure these sets computing the linear extremes $\left[v_{0}, v_{1}\right]$ for the case $\sigma=0$ and $\left[v_{1}, v 1_{1}\right]$ for $\sigma=1$. These extremes are simply the solutions of Eq. (12) solved at equality. 
Using the right and the left hand side of (12), the equilibrium domains for $\sigma=0,\left[v_{0}, v 1_{0}\right]$, and for $\sigma=1,\left[v_{1}, v 1_{1}\right]$, are respectively

$$
\left[v_{0}=\frac{\frac{R^{l}}{R^{h}}\left(1-\mu^{l}\right)}{\mu^{h}+\frac{R^{l}}{R^{h}}\left(1-\mu^{l}\right)}, v 1_{0}=\frac{1-\mu^{l}}{1+\mu^{h}-\mu^{l}}\right]
$$

and

$$
\left[v_{1}=\frac{\frac{R^{l}}{R^{h}}\left(1-\mu^{h}\right)}{\mu^{l}+\frac{R^{l}}{R^{h}}\left(1-\mu^{h}\right)}, v 1_{1}=\frac{1-\mu^{h}}{1-\mu^{h}+\mu^{l}}\right] .
$$

The larger is the interval for which equilibria exists under diversification or concentration, the larger is the set of economies that may benefit from the risk sharing opportunities offered by the interbank market.

Consider the difference between the equilibria interval when $\sigma=0$ and when $\sigma=1$, defined as:

$$
G \equiv \Delta_{0}-\Delta_{1}=\left(v_{0}-v 1_{0}\right)-\left(v_{1}-v 1_{1}\right) .
$$

Computations give:

$$
\Delta_{0}=\frac{\mu^{h}\left(1-\mu^{l}\right)\left(1-\frac{R^{l}}{R^{h}}\right)}{\left(1+\mu^{h}-\mu^{l}\right)\left(\mu^{h}+\frac{R^{l}}{R^{h}}\left(1-\mu^{l}\right)\right)},
$$

and

$$
\Delta_{1}=\frac{\mu^{l}\left(1-\mu^{h}\right)\left(1-\frac{R^{l}}{R^{h}}\right)}{\left(1-\mu^{h}+\mu^{l}\right)\left(\mu^{l}+\frac{R^{l}}{R^{h}}\left(1-\mu^{h}\right)\right)} .
$$

Of particular interest is the comparison of the set of equilibria for relatively large credit and liquidity shocks. This comparison is made clearer by substituting $\mu^{h}=\gamma \mu^{l}$, where $\frac{1}{\mu^{l}} \geq \gamma \geq 1$, and $R^{l}=\beta R^{h}$ where $\beta \leq 1$. Parameter $\gamma$ is a measure of the liquidity risk and $\beta$ is the credit risk. The smaller is $\beta$, the larger is the difference between high and low return. The larger is $\gamma$, the larger is the difference between low and high liquidity shock.

Thus, (15) can be expressed as

$$
G\left(\mu^{l}, \gamma, \beta\right)=\frac{\gamma \mu^{l}\left(1-\mu^{l}\right)}{\left(1+\gamma \mu^{l}-\mu^{l}\right)\left(\gamma \mu^{l}+\beta\left(1-\mu^{l}\right)\right)}-\frac{\mu^{l}\left(1-\gamma \mu^{l}\right)}{\left(1-\gamma \mu^{l}+\mu^{l}\right)\left(\mu^{l}+\beta\left(1-\gamma \mu^{l}\right)\right)} .
$$

The following proposition establishes a ranking of the size of equilibria under a diversified economy and a risk-concentrated economy.

Proposition 2. There exists a $\overline{\mu^{l}}$ such that for $\mu^{l} \geq \overline{\mu^{l}}$ and any $(\beta, \gamma)$ the set of interbank equilibrium under the diversified economy is always strictly larger than for the concentrated economy.

When liquidity shocks are large, the set of interbank equilibria of the diversified economy is larger than the corresponding set of the risk-concentrated economy and the interbank equilibrium is likely to break down for more model parameter ranges. Therefore, a diversified economy offers a better insurance against high liquidity and credit risk. Finally note that by (18), for $\beta=\gamma=1$, which amounts to absence of credit and liquidity risk, $G(1,1)=0$, then the two sets are equivalent. This means that bank market structure is important especially when the shocks are high.

Fig. 1 shows graphically the result of Proposition 2 for a set of economies. The surface representing the function $G\left(\mu^{l}, \gamma, \beta\right)$ is increasing in liquidity risk.

As Fig. 1 highlights, the set of equilibria is increasing in the degree of banks' risk diversification for a liquidity risk greater that $\bar{\mu}^{l}$. This indicates that an interbank is less likely to break-down when the economy is more diversified. 


$$
\mu^{l}=0.5
$$

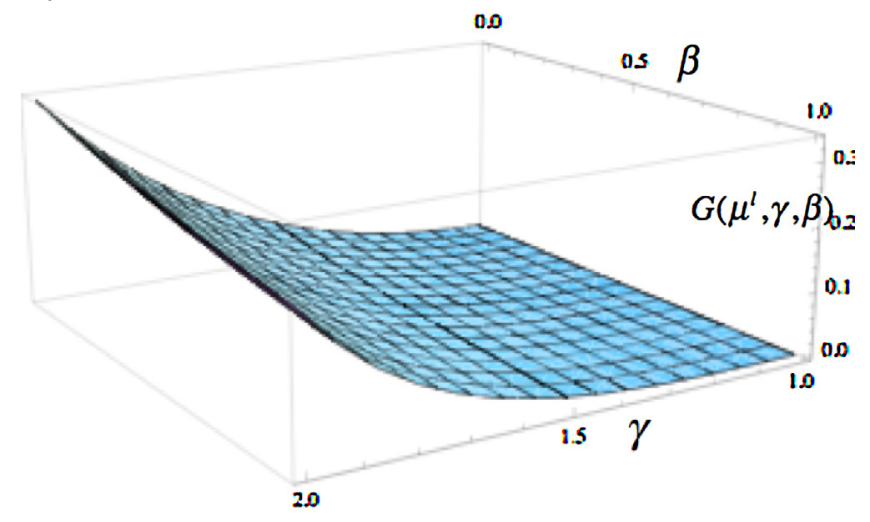

Fig. 1. Behavior of $G\left(\mu^{l}, \gamma, \beta\right)$.

\section{Welfare comparisons}

We want to compare agents' welfare in economies with banking systems differing according to market structure and risk concentration. To do that, we compute depositors' expected utility.

Using (2) and (3), the consumption in states 1 and 2 is

$$
c_{1}=\frac{\alpha \lambda+b}{\mu}
$$

and

$$
c_{2}=\frac{R(1-\alpha)-r b}{1-\mu} .
$$

Substituting equilibrium values $\alpha, b$ and $r$ in (19) and (20), we obtain the consumption allocation offered by different bank types, $C^{\text {type }(i)}=\left(c_{1}^{\text {type }(i)}, c_{2}^{\text {type(i) }}\right)$ for $i=1,2,3,4$ :

$$
\begin{aligned}
& C^{\text {type }(1)}=\left(\frac{\left[(1-\sigma)(1-q)\left(1-\mu^{l}\right)+\sigma(1-p)\left(1-\mu^{h}\right)\right] \lambda}{\sigma p \mu^{l}+(1-\sigma) q \mu^{h}}, R^{h}\right) \\
& C^{\text {type(2) }}=\left(\frac{\left[(1-\sigma)(1-q)\left(1-\mu^{l}\right)+\sigma(1-p)\left(1-\mu^{h}\right)\right] \lambda}{\sigma p \mu^{l}+(1-\sigma) q \mu^{h}}, R^{h}\right) \\
& C^{\text {type(3) }}=\left(\lambda, \frac{R^{h}\left(\sigma p \mu^{l}+(1-\sigma) q \mu^{h}\right)}{(1-\sigma)(1-q)\left(1-\mu^{l}\right)+\sigma(1-p)\left(1-\mu^{h}\right)}\right) \\
& C^{\text {type(4) }}=\left(\lambda, \frac{R^{h}\left(\sigma p \mu^{l}+(1-\sigma) q \mu^{h}\right)}{(1-\sigma)(1-q)\left(1-\mu^{l}\right)+\sigma(1-p)\left(1-\mu^{h}\right)}\right) .
\end{aligned}
$$

The ex-ante the expected utility of a representative consumer is therefore

$$
W \equiv \sum_{i=1}^{4} P(\text { type }(i)) U\left(c_{1}^{\text {type }(i)}, c_{2}^{\text {type }(i)}\right) \quad \text { for } i=1,2,3,4 .
$$

Equivalently:

$$
W \equiv \sigma p U\left(C^{\text {type }(1)}\right)+(1-\sigma) q U\left(C^{\text {type(2) }}\right)+(1-\sigma)(1-q) U\left(C^{\text {type(3) }}\right)+\sigma(1-p) U\left(C^{\text {type }(4)}\right) .
$$




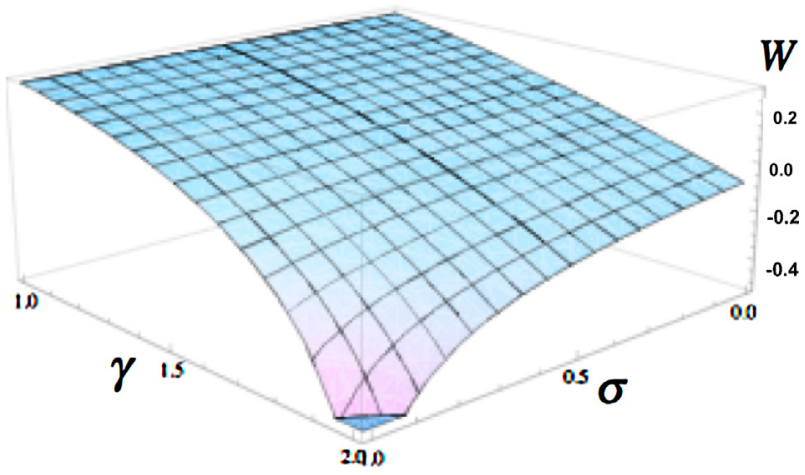

Fig. 2. The behavior of $W$ as a function of $\sigma$ and liquidity risk $\gamma$.

Unfolding (23) we get:

$$
\begin{aligned}
W \equiv & \sigma p\left(\mu^{l} \log \left(\frac{\left[(1-\sigma)(1-q)\left(1-\mu^{l}\right)+\sigma(1-p)\left(1-\mu^{h}\right)\right] \lambda}{\sigma p \mu^{l}+(1-\sigma) q \mu^{h}}\right)+\left(1-\mu^{l}\right) \log \left(R^{h}\right)\right) \\
& +(1-\sigma) q\left(\mu^{h} \log \left(\frac{\left[(1-\sigma)(1-q)\left(1-\mu^{l}\right)+\sigma(1-p)\left(1-\mu^{h}\right)\right] \lambda}{\sigma p \mu^{l}+(1-\sigma) q \mu^{h}}\right)+\left(1-\mu^{h}\right) \log \left(R^{h}\right)\right) \\
& +(1-\sigma)(1-q)\left(\mu^{l} \log (\lambda)+\left(1-\mu^{l}\right) \log \left(\frac{R^{h}\left(\sigma p \mu^{l}+(1-\sigma) q \mu^{h}\right)}{(1-\sigma)(1-q)\left(1-\mu^{l}\right)+\sigma(1-p)\left(1-\mu^{h}\right)}\right)\right) \\
& +\sigma(1-p)\left(\mu^{h} \log (\lambda)+\left(1-\mu^{h}\right) \log \left(\frac{R^{h}\left(\sigma p \mu^{l}+(1-\sigma) q \mu^{h}\right)}{(1-\sigma)(1-q)\left(1-\mu^{l}\right)+\sigma(1-p)\left(1-\mu^{h}\right)}\right)\right)
\end{aligned}
$$

Fig. 2 shows $W$ for given return parameters. Note that $W$ is decreasing both in $\sigma$ and in the liquidity risk parameter $\gamma$.

Fig. 2 shows that welfare decreases when banking system risk is concentrated and liquidity risk is high. The corner representing high levels of $\gamma$ and $\sigma$ can be viewed as a "crisis" set of risk realizations with high welfare losses.

When the interbank equilibrium does not exist, the autarkic allocation will prevail. Depositors' expected utility under autarky is given by the solution of the following problem:

$$
\underset{\alpha}{\operatorname{Max}} W^{A}=\mu U\left(c_{1}\right)+(1-\mu) U\left(c_{2}\right)
$$

Subject to

$$
\begin{aligned}
& \mu c_{1}=\alpha \lambda \\
& (1-\mu) c_{2}=R(1-\alpha) .
\end{aligned}
$$

The optimal solution is $\alpha^{*}=\mu$. Therefore, substituting in (2b) and (3b), the consumption allocations for each bank type at an autarkic equilibrium are:

$$
\begin{aligned}
& C^{\text {type(1) }}=C^{\text {type(2) }}=\left(\lambda, R^{h}\right) \\
& C^{\text {type(3) }}=C^{\text {type }(4)}=\left(\lambda, R^{l}\right) .
\end{aligned}
$$



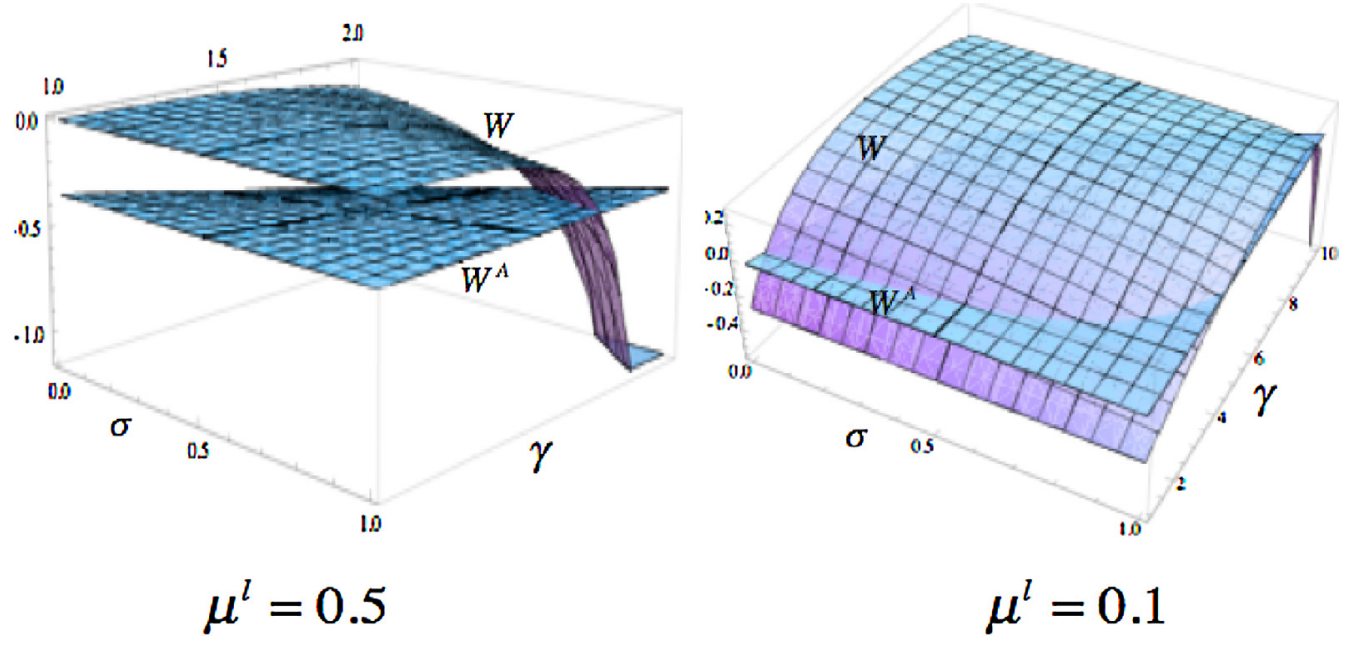

Fig. 3. Behavior of $W$ and $W^{A}$ with different liquidity shocks.

Correspondingly, the expected utility of an agent at the initial date is:

$$
\begin{aligned}
W^{A} \equiv & \sigma p\left[\mu^{l} \log (\lambda)+\left(1-\mu^{l}\right) \log \left(R^{h}\right)\right]+(1-\sigma) q\left[\gamma \mu^{l} \log (\lambda)+\left(1-\gamma \mu^{l}\right) \log \left(R^{h}\right)\right] \\
& +(1-\sigma)(1-q)\left[\mu^{l} \log (\lambda)+\left(1-\mu^{l}\right) \log \left(R^{l}\right)\right]+\sigma(1-p)\left[\gamma \mu^{l} \log (\lambda)+\left(1-\lambda \mu^{l}\right) \log \left(R^{l}\right)\right]
\end{aligned}
$$

Fig. 3 shows $W$, the expected utility when the interbank equilibrium exists, and $W^{A}$, the expected utility under autarky, as functions of $\sigma$ and $\gamma$ for two sets of economies. For high values of risk concentration and liquidity risk the interbank equilibrium does not exist, as $W^{A}>W$. When the interbank surface lies over the autarky plane, the interbank equilibrium exists since $W>W^{A}$ for all parameter values, with $W$ strictly decreasing in the degree of risk concentration $\sigma$.

Fig. 3 illustrates the general finding summarized in the following proposition 3 . The figure describes the existence of the interbank market and the welfare behavior for different levels of risk concentration and liquidity shocks. The corner with high liquidity shocks and high concentration is a crisis. In this case the interbank market will not exist since the autarky equilibrium (the plane $W^{A}$ ) gives higher welfare than the interbank equilibrium.

Proposition 3. (a) There exists $(\bar{\sigma}, \bar{\gamma})$ such that $W^{A}>W$ for all $(\sigma, \gamma)>(\bar{\sigma}, \bar{\gamma})$.

(b) When $W>W^{A}$ the interbank equilibrium exists, and $W$ is strictly decreasing in $\sigma$ for any $\gamma$.

It is useful to illustrate examples for different set of economies. Fig. 4 clearly shows that when $\sigma$ is high and liquidity risk, $\gamma$, is sufficiently high, the interbank allocation is dominated by the autarky allocation.

Fig. 5 shows that with high credit risk, i.e. low probability of realization of the high return, the interbank market is more likely to exist than the autarky allocation. This suggests that interbank markets insure against credit risk also, while $W$ remains decreasing with respect to $\sigma$.

The pictures 3, 4 and 5 highlight that welfare always decreases when the economy exhibits a high risks concentration and high liquidity exposure.

\section{An example of endogenous degree of risk concentration}

So far the degree of risk concentration in the banking system (parameter $\sigma$ ) has been treated as exogenous. We have shown that welfare decreases in the degree of market concentration. For all 


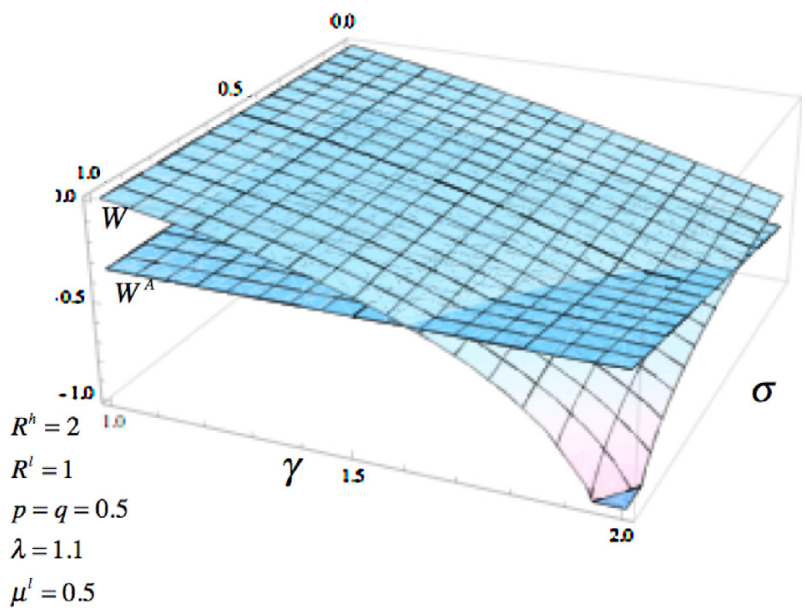

Fig. 4. $W$ and $W^{A}$ with relatively high $p$ and $q$.

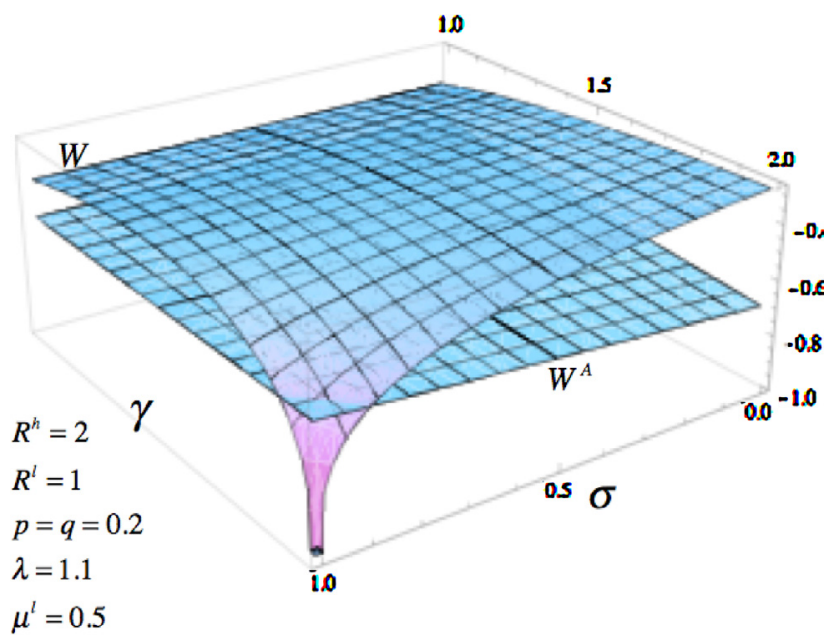

Fig. 5. $W$ and $W^{A}$ with relatively low $p$ and $q$.

examples shown, the highest depositors' expected utility is reached at the minimum level of risk concentration $(\sigma=0)$.

Recall that $\sigma$ is a parameter that determines the probabilities of credit and liquidity shocks as of date 0 . Therefore, a choice of $\sigma$ can be viewed as a bank choice of credit and liquidity risk. If achieving perfect diversification at a system level is costless, then in a perfectly competitive banking system, banks would choose the minimum level of risk concentration and the probability of interbank market breakdowns would be minimized.

In reality, Shehzad and De Haan (2013) suggest that stock prices of large banks were affected more during the crisis than those of small banks and they also find that managerial efficiency, loan quality, leverage, and the volume of outstanding loans affect bank stock prices. Literally, achieving diversification and controlling risk is costly, since risk management can be viewed as a technology available to firms similar, for example, to the technology underlying credit risk models. As the size and scope of the operations of banks expands, financial firms' span of control over their many units can become less efficient in controlling risk. In this light, a lack of sufficient banking system diversification 
and a higher probability of interbank market breakdowns may be in part due to risk control diseconomies of scale and scope.

The potential for first order effects of risk management diseconomies of scale and scope on risk concentration in the banking system, and their relationship with bank size, can be illustrated by the following modification of our model.

Suppose at date 0 banks have a size $S \geq 0$, and choose $\sigma$ employing part of date 0 resources. Specifically, they invest a fraction $x$ of date resources in the technology and choose $\sigma$ incurring a cost $z(\sigma) S^{\phi}$ as a fraction of date 0 resources, where $\phi>0$ is the scale cost parameter. Their resource constraint at date 0 is therefore:

$$
x+z(\sigma) S^{\phi}=S
$$

Assume $z(\sigma)=\frac{a_{0}}{\sigma}+a_{1} \sigma$, with $a_{0}$ and $a_{1}$ as positive coefficients. This function can be interpreted as a cost function of a risk control technology that exhibits decreasing returns to investment over a certain threshold. Its parameters could depend on size and scope of financial firms operations, as well as on incentives arising from asymmetric information, market power and other factors pointed out in the literature, which may in turn be affected by firms' size.

To compute $W(\sigma)$, we replace 1 with $S\left(1-z(\sigma) S^{\phi}\right)$ in the consumption allocations,

$$
c_{1}=\frac{\alpha \lambda S\left(1-z(\sigma) S^{\phi}\right)+b}{\mu}
$$

and

$$
c_{2}=\frac{R(1-\alpha) S\left(1-z(\sigma) S^{\phi}\right)-r b}{1-\mu} .
$$

Then, optimal borrowing/lending choices in the interbank market are:

$$
b(R, \mu)=\frac{S\left(1-z(\sigma) S^{\phi}\right)}{r}\left(\mu R\left(1-\alpha^{*}\right)-r(1-\mu) \alpha^{*} \lambda\right),
$$

With the liquidation choices $\alpha$ unchanged, the equilibrium in the interbank market is the solution of the following equation:

$$
\begin{aligned}
& \sigma p \frac{S\left(1-z(\sigma) S^{\phi}\right)}{r} \mu^{l} R^{h}+(1-\sigma) q \frac{S\left(1-z(\sigma) S^{\phi}\right)}{r} \mu^{h} R^{h}-(1-\sigma)(1-q) S\left(1-z(\sigma) S^{\phi}\right)\left(1-\mu^{l}\right) \lambda \\
& -\sigma(1-p) S\left(1-z(\sigma) S^{\phi}\right)\left(1-\mu^{h}\right) \lambda=0
\end{aligned}
$$

which yields

$$
r^{*}=\frac{R^{h}\left(\sigma p \mu^{l}+(1-\sigma) q \mu^{h}\right)}{\left[(1-\sigma)(1-q)\left(1-\mu^{l}\right)+\sigma(1-p)\left(1-\mu^{h}\right)\right] \lambda} .
$$

Note that (32) is equivalent to (11), meaning that the equilibrium interbank rate does not depend on the function $S\left(1-z(\sigma) S^{\phi}\right)$. This means that in the market for liquidity is the excess of demand on supply that determines interbank rate. Multiplying both demand and supply for the size function would not affect the equilibrium interbank rate.

The consumption allocations for the four bank types which allow us to compute depositors' expected utility are:

$$
C^{\text {type(1) }}=\left(\frac{\left[(1-\sigma)(1-q)\left(1-\mu^{l}\right)+\sigma(1-p)\left(1-\mu^{h}\right)\right] \lambda S\left(1-z(\sigma) S^{\phi}\right)}{\sigma p \mu^{l}+(1-\sigma) q \mu^{h}}, R^{h} S\left(1-z(\sigma) S^{\phi}\right)\right)
$$




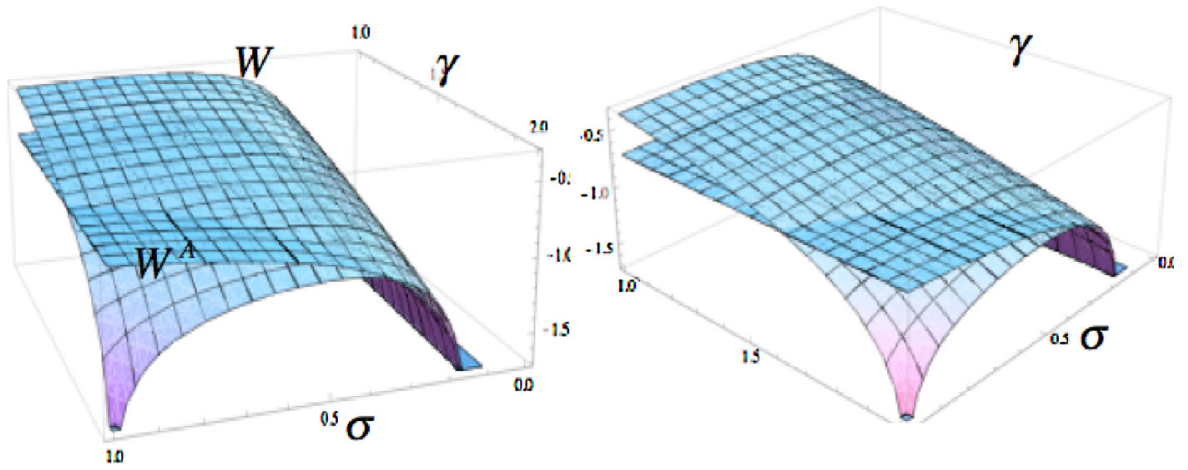

$$
\begin{array}{ll}
R^{h}=2 & a_{0}=0.1 \\
R^{l}=1 & a_{1}=0.2 \\
p=q=0.5 & \\
\lambda=1.1 & \\
\mu^{l}=0.5 &
\end{array}
$$

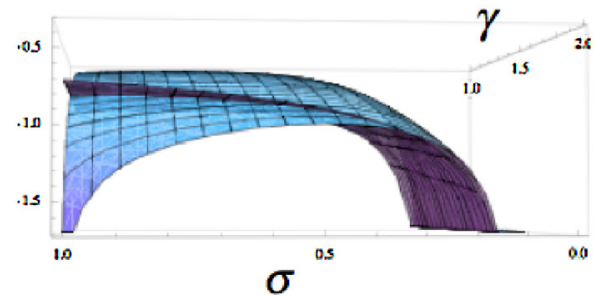

Fig. 6. Expected utility $W$ with costs of risk $\operatorname{control} \phi=1$ and $S=4$.

$$
\begin{aligned}
& C^{\text {type }(2)}=\left(\frac{\left[(1-\sigma)(1-q)\left(1-\mu^{l}\right)+\sigma(1-p)\left(1-\mu^{h}\right)\right] \lambda S\left(1-z(\sigma) S^{\phi}\right)}{\sigma p \mu^{l}+(1-\sigma) q \mu^{h}}, R^{h} S\left(1-z(\sigma) S^{\phi}\right)\right) \\
& C^{\text {type(3) }}=\left(\lambda S\left(1-z(\sigma) S^{\phi}\right), \frac{R^{h}\left(\sigma p \mu^{l}+(1-\sigma) q \mu^{h}\right) S\left(1-z(\sigma) S^{\phi}\right)}{(1-\sigma)(1-q)\left(1-\mu^{l}\right)+\sigma(1-p)\left(1-\mu^{h}\right)}\right) \\
& C^{\text {type(4) }}=\left(\lambda S\left(1-z(\sigma) S^{\phi}\right), \frac{R^{h}\left(\sigma p \mu^{l}+(1-\sigma) q \mu^{h}\right) S\left(1-z(\sigma) S^{\phi}\right)}{(1-\sigma)(1-q)\left(1-\mu^{l}\right)+\sigma(1-p)\left(1-\mu^{h}\right)}\right) .
\end{aligned}
$$

Fig. 6 shows (with different angles) an example of the expected utility function $W$ as a function of $\sigma$ and the liquidity risk parameter $\gamma$. It is apparent that function $W$ is strictly concave, with a maximum for $\sigma$ as an interior point. We plot the surface for size parameter $S=4$ and $\phi=1$.

Proposition 4. For any value of $\phi$ and for a given level of liquidity risk $\bar{\gamma}$, the optimal bank risk concentration level $\sigma^{*}$ is increasing in $S$.

Proposition 4 states that the scale parameter $\phi$ is the determinant of the degree of diversification that a bank chooses, and bank diversification is inversely related to its assets size.

Fig. 6 shows the concavity property of the welfare function in the case of costly diversification. This implies the choice of a $\sigma$ different from 0 .

Fig. 7 shows the optimal $\sigma$ for different bank size. The maximum of the expected utility is different according to $S$. The concentration is greater for a bank size larger than one. By contrast, for a small bank size the optimal risk concentration approaches zero.

Therefore, the optimal level of risk concentration might be larger than the minimum feasible. In turn, risk concentration is larger for a larger bank size. The level of $a_{0}$ and $a_{1}$ may depend fundamentally on market structure, that is on the distribution of firms by size. As a result, any incentive to increase 


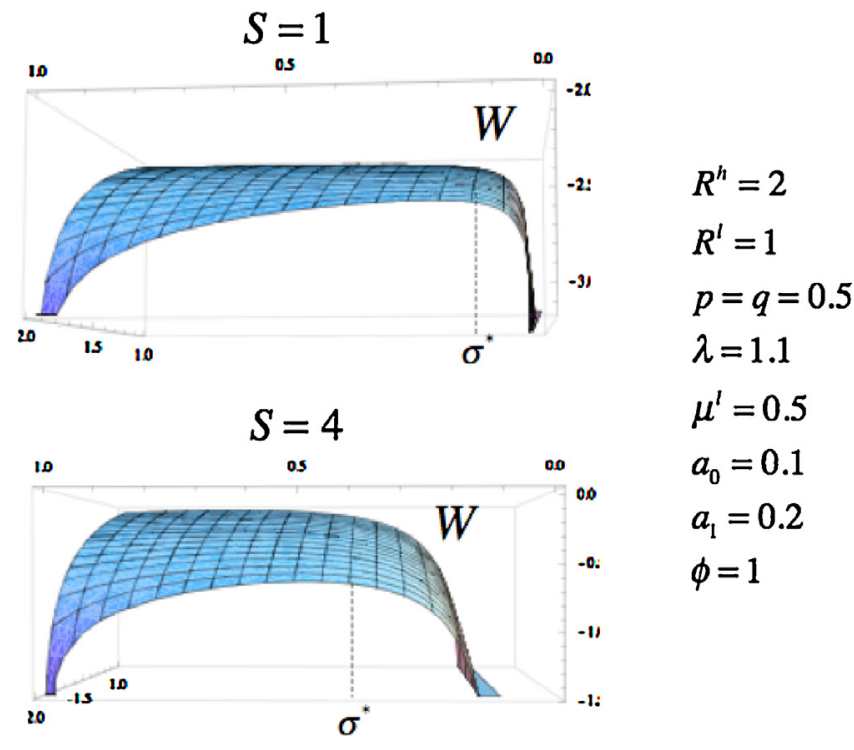

Fig. 7. Expected utility $W$ for $S=1$ and $S=4$.

financial firms' size, such as too-big-to-fail incentives, may carry higher risk control costs, which in turn could result in a higher level of risk concentration in the banking system.

\section{Conclusion}

Our model shows that risk concentration seems of first order importance for the smooth functioning of interbank markets. Risk concentration may increase in bank size under reasonable assumptions about the risk management technology available to banks. Differing from most literature, our results are obtained in a model with no asymmetric information, no market power or dysfunctional secondary markets.

With regard to policy, the literature has prominently focused on the important role of the Central Bank as lender of last resort when interbank market breakdowns occur (see e.g. Freixas, Parigi, \& JeanCharles, 2000; Freixas, Antoine, \& Skeie, 2009; Goodhart \& Illing, 2002; Repullo, 2005). Our model suggests that the improvement of risk management technologies in large and complex financial institutions, as well as in regulatory bodies, may be as important to minimize the occurrence of interbank market breakdowns.

\section{Acknowledgements}

I acknowledges financial support under the project SYRTO, funded by the European Union under the 7th Framework Programme (FP7-SSH/2007-2013 - Grant Agreement ${ }^{\circ}$ 320270) and the project MISURA, funded by the Italian MIUR.

The research leading to these results has received funding from the European Union, Seventh Framework Programme FP7/2007-2013 under grant agreement SYRTO-SSH-2012-320270.

I thank without implications the seminar Institute and the Deutsche Bundesbank for comments and suggestions. 


\section{Appendix.}

Proposition 1. For the perfectly diversified economy $(\sigma=0)$ and for the perfectly concentrated economy $(\sigma=1)$, the set of interbank equilibrias is non-empty for any parameter configuration of credit and liquidity risk $\left(\mu^{h}, \mu^{l}, R^{h}, R^{l}\right)$.

Proof. The left-hand side inequality of (12) can be expressed as:

$$
\begin{aligned}
& (1-\sigma)\left(1+\mu^{h}-\mu^{l}\right) q \leq(1-\sigma)\left(1-\mu^{l}\right)+\sigma\left(1-\mu^{h}\right)-p \sigma\left(1-\mu^{h}+\mu^{l}\right), \\
& \text { If } \sigma=0, \text { then }\left(1+\mu^{h}-\mu^{l}\right) q \leq\left(1-\mu^{l}\right) \\
& \text { If } \sigma=1, \text { then } 0 \leq\left(1-\mu^{h}\right)-p\left(1-\mu^{h}+\mu^{l}\right)
\end{aligned}
$$

The right-hand side inequality of (12) can be expressed as:

$$
\begin{aligned}
& (1-\sigma)\left(\mu^{h}+\frac{R^{l}}{R^{h}}\left(1-\mu^{l}\right)\right) \geq \frac{R^{l}}{R^{h}}\left[\sigma\left(1-\mu^{h}\right)+(1-\sigma)\left(1-\mu^{l}\right)\right]-p \sigma\left[\left(1-\mu^{h}\right) \frac{R^{l}}{R^{h}}+\mu^{l}\right] \\
& \text { If } \sigma=0, \quad \text { then } q\left(\mu^{h}+\frac{R^{l}}{R^{h}}\left(1-\mu^{l}\right)\right) \geq \frac{R^{l}}{R^{h}}\left(1-\mu^{l}\right) \\
& \text { If } \sigma=1, \quad \text { then } 0 \geq \frac{R^{l}}{R^{h}}\left(1-\mu^{h}\right)-p\left[\left(1-\mu^{h}\right) \frac{R^{l}}{R^{h}}+\mu^{l}\right]
\end{aligned}
$$

Thus, the set of economies for which an interbank equilibrium exists is indexed by $q \in[0,1]$ if $\sigma=0$, and by $p \in[0,1]$ if $\sigma=1$.

If $\sigma=0$, using (A2) and (A5), we get:

$$
\frac{\frac{R^{l}}{R^{h}}\left(1-\mu^{l}\right)}{\mu^{h}+\frac{R^{l}}{R^{h}}\left(1-\mu^{l}\right)} \leq q \leq \frac{1-\mu^{l}}{1+\mu^{h}-\mu^{l}} .
$$

Therefore, if $\sigma=0$, the set of interbank equilibria is non-empty if

$$
\frac{1-\mu^{l}}{1+\mu^{h}-\mu^{l}} \geq \frac{\frac{R^{l}}{R^{h}}\left(1-\mu^{l}\right)}{\mu^{h}+\frac{R^{l}}{R^{h}}\left(1-\mu^{l}\right)} .
$$

Inequality (A8) implies that $\left(1-\mu^{l}\right)\left(\mu^{h}+\frac{R^{l}}{R^{h}}\left(1-\mu^{l}\right)\right) \geq \frac{R^{l}}{R^{h}}\left(1-\mu^{l}\right)\left(1+\mu^{h}-\mu^{l}\right)$, which can be further simplified to $\mu^{h} \geq \frac{R^{l}}{R^{h}} \mu^{h}$, which in turn is always verified since $\frac{R^{l}}{R^{h}}<1$.

If $\sigma=1$, using (A3) and (A6) we get:

$$
\frac{1-\mu^{h}}{1-\mu^{h}+\mu^{l}} \geq p \geq \frac{\frac{R^{l}}{R^{h}}\left(1-\mu^{h}\right)}{\mu^{l}+\frac{R^{l}}{R^{h}}\left(1-\mu^{h}\right)} .
$$

Inequality (A9) is always satisfied, since it reduces to $\mu^{l} \geq \frac{R^{l}}{R^{h}} \mu^{l}$, which holds as $\frac{R^{l}}{R^{h}}<1 . \square$

Proposition 2. There exists a $\overline{\mu^{l}}$ such that for $\mu^{l} \geq \overline{\mu^{l}}$ and any $(\gamma, \beta)$ the set of interbank equilibrium under the diversified economy is always strictly larger than for the concentrated economy.

Proof. Differentiating (18) with respect to $\mu^{l}$, and evaluating the derivative at $\mu^{l}=1$ :

$$
G_{\mu^{l}}(0, \gamma, \beta) \simeq \frac{(\gamma-1)\left(4(1+\beta)^{2}+\gamma^{2} \beta(1+5 \beta)-\gamma^{3} \beta^{2}-\gamma\left(1+7 \beta+8 \beta^{2}\right)\right)}{(\gamma-2)^{2} \gamma(\beta(\gamma-1)-1)^{2}},
$$

since $(\gamma-1)>0$ and $(\gamma-2)^{2} \gamma(\beta(\gamma-1)-1)^{2}>0,($ A10) is positive if

$$
4(1+\beta)^{2}+\gamma^{2} \beta(1+5 \beta)>\gamma^{3} \beta^{2}+\gamma\left(1+7 \beta+8 \beta^{2}\right) .
$$


Observe that for $\mu^{l} \rightarrow 1, \gamma \rightarrow 1$, then (A11) reduces to

$$
3+2 \beta>0 \text {. }
$$

Therefore, there exist values of $\bar{\mu}^{l}$ and $\bar{\gamma}$ such that for $\mu^{l} \geq \overline{\mu^{l}}$ and for $\gamma \geq \bar{\gamma}$ the function $G\left(\mu^{l}, \gamma, \beta\right)$ is increasing. $\square$

Proposition 3. (c) There exists $(\bar{\sigma}, \bar{\gamma})$ such that $W^{A}>W$ for all $(\sigma, \gamma)>(\bar{\sigma}, \bar{\gamma})$;

(d) When $W>W^{A}$ the interbank equilibrium exists, and $W$, is strictly decreasing in $\sigma$ for any $\gamma$.

Proof. We prove part (a) and (b) separately.

(a) There is a $(\sigma, \gamma)>(\bar{\sigma}, \bar{\gamma})$ such that the autarky allocation dominates the interbank equilibrium. The expected utility under autarky for $\sigma=0$ and for $\sigma=1$ are

$$
W^{A 0} \equiv q\left[\gamma \mu^{l} \log (\lambda)+\left(1-\gamma \mu^{l}\right) \log \left(R^{h}\right)\right]+(1-q)\left[\mu^{l} \log (\lambda)+\left(1-\mu^{l}\right) \log \left(R^{l}\right)\right],
$$

and

$$
W^{A 1} \equiv p\left[\mu^{l} \log (\lambda)+\left(1-\mu^{l}\right) \log \left(R^{h}\right)\right]+(1-p)\left[\gamma \mu^{l} \log (\lambda)+\left(1-\lambda \mu^{l}\right) \log \left(R^{l}\right)\right] .
$$

Hence, we compare the expected utility within a diversify economy between interbank allocation and autarky allocation

$$
\begin{aligned}
& W^{0}-W^{A 0} \equiv q\left(\gamma \mu^{l} \log \left(\frac{(1-q)\left(1-\mu^{l}\right) \lambda}{q \gamma \mu^{l}}\right)+\left(1-\gamma \mu^{l}\right) \log \left(R^{h}\right)\right) \\
& +(1-q)\left(\mu^{l} \log (\lambda)+\left(1-\mu^{l}\right) \log \left(\frac{R^{h} q \gamma \mu^{l}}{(1-q)\left(1-\mu^{l}\right)}\right)\right)-\left\{q\left[\gamma \mu^{l} \log (\lambda)+\left(1-\gamma \mu^{l}\right) \log \left(R^{h}\right)\right]\right. \\
& \left.+(1-q)\left[\mu^{l} \log (\lambda)+\left(1-\mu^{l}\right) \log \left(R^{l}\right)\right]\right\} \Rightarrow q\left(\gamma \mu^{l}\left(\log \left(\frac{(1-q)\left(1-\mu^{l}\right) \lambda}{q \gamma \mu^{l}}\right)-\log (\lambda)\right)\right) \\
& +(1-q)\left(\left(1-\mu^{l}\right)\left(\log \left(\frac{R^{h} q \gamma \mu^{l}}{(1-q)\left(1-\mu^{l}\right)}\right)-\log \left(R^{l}\right)\right)\right),
\end{aligned}
$$

The difference of expected utility in a risk concentrated economy between the interbank allocation and autarky allocation is

$$
\begin{aligned}
& W^{1}-W^{A 1} \equiv p\left(\mu^{l} \log \left(\frac{(1-p)\left(1-\gamma \mu^{l}\right) \lambda}{p \mu^{l}}\right)+\left(1-\mu^{l}\right) \log \left(R^{h}\right)\right)+(1-p)\left(\gamma \mu^{l} \log (\lambda)\right. \\
& \left.+\left(1-\gamma \mu^{l}\right) \log \left(\frac{R^{h} p \mu^{l}}{(1-p)\left(1-\gamma \mu^{l}\right)}\right)\right)-\left\{p\left[\mu^{l} \log (\lambda)+\left(1-\mu^{l}\right) \log \left(R^{h}\right)\right]\right. \\
& \left.+(1-p)\left[\gamma \mu^{l} \log (\lambda)+\left(1-\lambda \mu^{l}\right) \log \left(R^{l}\right)\right]\right\} \Rightarrow p\left(\mu^{l}\left(\log \left(\frac{(1-p)\left(1-\gamma \mu^{l}\right) \lambda}{p \mu^{l}}\right)-\log (\lambda)\right)\right) \\
& +(1-p)\left(\left(1-\gamma \mu^{l}\right)\left(\log \left(\frac{R^{h} p \mu^{l}}{(1-p)\left(1-\gamma \mu^{l}\right)}\right)-\log \left(R^{l}\right)\right)\right) .
\end{aligned}
$$

Computing (A15) and (A16) for $\gamma \rightarrow \frac{1}{\mu^{l}}, W^{0}-W^{A 0}>0$, and $W^{1}-W^{A 1}<0$. Then, we conclude that there exist a couple $(\sigma, \gamma)>(\bar{\sigma}, \bar{\gamma})$ such that the autarky allocation gives a higher expected utility than the interbank market equilibrium.

(b) When we have an interbank equilibrium, the expected utility decreases in $\sigma$. Take the derivative of (24) with respect to $\sigma$ and compute it for $\sigma \rightarrow 1$ and for $\gamma \rightarrow \frac{1}{\mu^{l}}$,

$$
W_{\sigma \rightarrow 1}\left(\gamma \rightarrow \frac{1}{\mu^{l}}\right) \rightarrow-\gamma<0 .
$$


Compute the derivative also for $\mu^{l} \rightarrow 0$

$$
W_{\sigma \rightarrow 1}\left(\mu^{l} \rightarrow 0\right)<0 \text {. }
$$

Therefore, as risk concentration increases, the expected utility in the interbank economy is decreasing. Moreover, the expected utility for $\sigma=0$ and for $\sigma=1$ are

$$
\begin{gathered}
W^{0} \equiv q\left(\gamma \mu^{l} \log \left(\frac{(1-q)\left(1-\mu^{l}\right) \lambda}{q \gamma \mu^{l}}\right)+\left(1-\gamma \mu^{l}\right) \log \left(R^{h}\right)\right) \\
\quad+(1-q)\left(\mu^{l} \log (\lambda)+\left(1-\mu^{l}\right) \log \left(\frac{R^{h} q \gamma \mu^{l}}{(1-q)\left(1-\mu^{l}\right)}\right)\right)
\end{gathered}
$$

and

$$
\begin{aligned}
& W^{1} \equiv p\left(\mu^{l} \log \left(\frac{(1-p)\left(1-\gamma \mu^{l}\right) \lambda}{p \mu^{l}}\right)+\left(1-\mu^{l}\right) \log \left(R^{h}\right)\right) \\
& \quad+(1-p)\left(\gamma \mu^{l} \log (\lambda)+\left(1-\gamma \mu^{l}\right) \log \left(\frac{R^{h} p \mu^{l}}{(1-p)\left(1-\gamma \mu^{l}\right)}\right)\right) .
\end{aligned}
$$

Let $\gamma \rightarrow \frac{1}{\mu^{l}}$, the difference of expected utilities is

$$
\begin{aligned}
& W^{0}-W^{1}=q\left(\log \left(\frac{(1-q)\left(1-\mu^{l}\right) \lambda}{q}\right)\right) \\
& +(1-q)\left(\mu^{l} \log (\lambda)+\left(1-\mu^{l}\right) \log \left(\frac{R^{h} q}{(1-q)\left(1-\mu^{l}\right)}\right)\right) \\
& -\left(p\left(\mu^{l} \log (\simeq 0)+\left(1-\mu^{l}\right) \log \left(R^{h}\right)\right)+(1-p) \log (\lambda)\right)>0,
\end{aligned}
$$

since $W^{1}\left(\gamma \rightarrow \frac{1}{\mu^{l}}\right)<0$ and $W^{0}\left(\gamma \rightarrow \frac{1}{\mu^{l}}\right)>0$.

Let $\mu^{l} \rightarrow 0$,

$$
W^{0}-W^{1} \rightarrow 0 .
$$

We conclude that for any $\gamma$ the expected utility decreases in concentration, $\sigma$.

Proposition 4. For any value of $\phi$ and for a given level of liquidity risk $\bar{\gamma}$, the optimal bank risk concentration level $\sigma^{*}$ is increasing in $S$.

Proof. Take the optimal $\sigma^{*}$ solving $W$ for a given level of liquidity risk $\bar{\gamma}$ and for $p=q=0.5$. For $S \rightarrow 0$, we have that $\sigma^{*} \rightarrow 0$ and for $S \rightarrow \infty \sigma^{*} \rightarrow 1 . \square$

\section{References}

Acharya, V. V., \& Merrouche, O. (2013). Precautionary hoarding of liquidity and interbank markets: Evidence from the subprime crisis. Review of Finance, 17(1), 107-160.

Acharya, V. V., \& Skeie, D. (2011). A model of liquidity hoarding and term premia in interbank markets. Journal of Monetary Economics, 58.

Acharya, V. V., Gromb, D., \& Yorulmazer, T. (2012). Imperfect competition in the interbank market for liquidity as a rationale for central banking. American Economic Journal: Macroeconomics, 4(2).

Acharya, V., \& Yorulmazer, T. (2008). Information contagion and bank herding. Journal of Money Credit and Banking, 40, $215-231$. Afonso, G., Kovner, X., \& Schoar, A. (2011). Stressed, not frozen - The fed funds market and the crisis of 2007/2008. Journal of Finance, 60.

Allen, F., \& Gale, D. (2007). Understanding financial crises. Oxford, UK: Oxford University Press, Clarendon Lectures in Finance.

Anand, K., Gai, P., \& Marsilli, M. (2012). Rollover risk, network structure and systemic risk. Journal of Economics Dynamics and Control, 36, 1088-1100.

Bhattacharya, S., \& Gale, D. (1987). Preference Shocks, Liquidity and Central Bank Policy. New approaches to monetary economics, Edited by William Barnett and Kenneth Singleton. Cambridge University Press. 
Boyd, J. H., De Nicolò, G., \& Loukoianova, E. (2009). Banking crises and crisis dating: Theory and evidence. In IMF Working Paper 09/141.

Boyd, J. H., De Nicolò, G., \& Jalal, A. M. (2009). Bank competition, risk and asset allocations. In IMF Working Paper 09/143.

Brunnermeier, M. K. (2009). Deciphering the liquidity and credit crunch 2007-2008. The Journal of Economic Perspectives, 77-100.

Cai, J., \& Thakor, A. V. (2008). Liquidity risk, credit risk, and interbank competition. In Working paper Olin Business School, W.D.C.

Ciccarelli, M., Maddaloni, A., \& Peydró, J. L. (2013). Heterogeneous transmission mechanism: Monetary policy and financial fragility in the eurozone. Economic Policy, 28(75), 459-512.

Cornett, M. M., McNutt, J. J., Strahan, P. E., \& Tehranian, H. (2011). Liquidity risk management and credit supply in the financial crisis. Journal of Financial Economics, 101(2), 297-312.

Covitz, D., \& Downing, C. (2007). Liquidity or credit risk? The determinants of very short-term corporate yield spreads. The Journal of Finance, 62(5), 2303-2328.

Da Silva, M. S., \& Divino, J. A. (2013). The role of banking regulation in an economy under credit risk and liquidity shock. The North American Journal of Economics and Finance, 26, 266-281.

De Nicolò, G., \& Kwast, M. L. (2002). Systemic risk and financial consolidation: Are they related? Journal of Banking E' Finance, 26, 861-880.

De Nicolò, G., Hayward, P., \& Bhatia, A. V. (2004). U.S. Large Complex Banking Groups: Business strategies, risks and surveillance issues. In IMF Country Report 04/228, July. Washington: International Monetary Fund.

De Nicolò, G., Bartholomew, P., Zaman, J., \& Zephirin, M. (2004). Bank consolidation, internationalization and conglomeration: Trends and implications for financial risk. Financial Markets Institutions E Instruments, 13(4), 173-217.

Diamond, D. W., \& Dybvig, P. H. (1983). Bank runs, deposit insurance, and liquidity. The Journal of Political Economy, 91(3), 401-419.

Diamond, D. W., \& Rajan, R. G. (2005). Liquidity shortages and banking crises. Journal of Finance, 60, 615-647.

Diamond, D. W., \& Rajan, R. G. (2008). Illiquidity and interest rate policy. In Working paper. University of Chicago.

ECB. (2009 December). Financial stability review. European Central Bank Frankfurt Am Main.

Ericsson, J., \& Renault, O. (2006). Liquidity and credit risk. The Journal of Finance, 61(5), 2219-2250.

Flannery, M. J. (1996). Financial crises, payment system problems and discount window lending. Journal of Money Credit and Banking, 28, 804-824.

Freixas, X., Parigi, B. M., \& Rochet, J.-C. (2000). Systemic risk, interbank relations, and liquidity provision by the Central Bank. Journal of Money, Credit and Banking, 32(3), 611-638.

Freixas, X., Martin, A., \& Skeie, D. (2009). Bank liquidity interbank markets, and monetary policy. Federal Reserve Bank of New York Staff Report N. 371.

Freixas, X., \& Jorge, J. (2008). The role of interbank markets in monetary policy: A model with rationing. Journal of Money, Credit and Banking, 40(6), 1151-1176.

Furfine, C. H. (2000). Interbank payments and the daily federal funds rate. Journal of Monetary Economics, 46, 535-553.

Gai, P., Haldane, A., \& Kapadia, S. (2011). Complexity and contagion. Journal of Monetary Economics, 58, 453-470.

Gale, D., \& Yorulmazer, T. (2012). Liquidity hoarding, staff report 488 Federal Reserve Bank of New York. In Forthcoming in theoretical economics.

Georg, C. P. (2013). The effect of the interbank network structure on contagion and common shocks. Journal of Banking E' Finance, 37(7), 2216-2228.

Giulioni, G. (2015). Policy interest rate, loan portfolio management and bank liquidity. The North American Journal of Economics and Finance, 31, 52-74.

Gorton, G., \& Huang, L. L. (2004). Liquidity, efficiency and bank bailouts. American Economic Review, 94, 455-483.

Gorton, G., \& Huang, L. L. (2006). Banking panics and endogeneity coalition formation. Journal of Monetary Economics, 53, $1613-1629$.

Goodhart, C., \& Illing, G. (2002). Financial crises contagion, and the lender of last resort. Oxford University Press.

Group of Ten. (2001). Report on consolidation in the financial sector, January, Basel.

Hartmann, P., Straetsman, S., \& de Vries, C. (2005). Banking system stability: A cross-Atlantic perspective, Working Paper No. 527 September. Frankfurt: European Central Bank.

Heider, F., Hoerova, M., \& Holthausen, C. (2010). Liquidity hoarding and interbank markets spreads: The role of counterparty risk. In CEPR Discussion Papers: 7762.

Houston, J. F., \& Stiroh, K. J. (2006). Three decades of financial sector risk, “U.S. Financial Holding Companies,” July. New York: Federal Reserve Bank of New York (unpublished).

Ibragimov, R., Jaffee, D., \& Walden, J. (2011). Diversification disasters. Journal of Financial Economics, 99, 333-348.

Miralles-Marcelo, J. L., del Mar Miralles-Quirós, M., \& Miralles-Quirós, J. L.(2015). Improving international diversification benefits for US investors. The North American Journal of Economics and Finance, 32, 64-76.

Repullo, R. (2005). Liquidity, risk taking, and the lender of last resort. International Journal of Central Banking, 2, 47-80.

Shehzad, C. T., \& De Haan, J. (2013). Was the 2007 crisis really a global banking crisis? The North American Journal of Economics and Finance, 24, 113-124.

Stiroh, K. J. (2004). Diversification in banking: Is noninterest income the answer? Journal of Money Credit and Banking, 36(5), $853-882$.

Stiroh, K. J., \& Rumble, A. (2006). The dark side of diversification: The case of U.S. Financial Holding Companies. Journal of Banking and Finance, 30(8), 2131-2161.

Wagner, W. (2010). Diversification at financial institutions and systemic crises. Journal of Financial Intermediation, 19, 333-354.

Wagner, W. (2011). Systemic liquidation risk and the diversity-diversification trade-off. Journal of Finance, 66(4), $1141-2117$. 